\title{
Investigation of 2-Hydroxyacetophenone Nicotinic Acid Hydrazone as a Fluoride Sensor
}

\section{Noorain Khalifa, Shibin Jasper Thomas, Nithin Kota Vasudeva Upadhya, Sreeja Puthenveettil Balakrishnan*}

Department of Chemistry, CHRIST (Deemed to Be University), Bengaluru, India

Email address:

sreeja.pb@christuniversity.in (S. P. Balakrishnan)

${ }^{*}$ Corresponding author

\section{To cite this article:}

Noorain Khalifa, Shibin Jasper Thomas, Nithin Kota Vasudeva Upadhya, Sreeja Puthenveettil Balakrishnan. Investigation of 2Hydroxyacetophenone Nicotinic Acid Hydrazone as a Fluoride Sensor. International Journal of Computational and Theoretical Chemistry. Vol. 7, No. 1, 2019, pp. 28-34. doi: 10.11648/j.ijctc.20190701.15

Received: January 29, 2019; Accepted: March 11, 2019; Published: March 25, 2019

\begin{abstract}
In the present work, we studied the selective chemosensing behavior of 2- hydroxyacetophenone nicotinic acid hydrazone $\left(\mathrm{H}_{2} \mathrm{~L}\right)$ with fluoride anion. Theoretical and experimental tools were deployed to understand the mechanism of sensing. Experimentally, upon the addition of fluoride to $\mathrm{H}_{2} \mathrm{~L}$, a change in colour was observed. The ${ }^{1} \mathrm{H}$ NMR spectral studies showed a change in electronic environment around the $\mathrm{N}-\mathrm{H}$ and $\mathrm{O}-\mathrm{H}$ bonding sites of the receptor. UV visible spectrum confirmed the formation of a new complex and IR spectrum showed the absence of the hydrogen bond donor peaks. Density Functional Theory (DFT) calculations were carried out in ground state and they were found to be in accordance with the experimental results.
\end{abstract}

Keywords: Colorimetric Sensor, IR Sensing, Fluoride Anion Recognition, Hydrogen Bonding, DFT Calculations, Acoyl Hydrazones

\section{Introduction}

Recognition of anions has become a formidable area of research, of which fluoride anion is a vital component $[1,2]$. Fluoride, the smallest and the most electronegative anion, has clinched a lot of attention due to its involvement in biomedical, environmental and chemical processes [3-5]. Regulated use of fluoride can be a potential cure for osteoporosis $[6,7]$ and hence artificial fluorination of water has helped to serve several bone and teeth related problems. But fluoride consumptions above $20-100 \mathrm{mg}$ on a daily basis could cause severe medical disorders like abnormal increase in skeletal mass, sclerosis, etc. Further, fluoride level in water and environment greatly influences the animal and plant growth [8]. Thus, the indication of fluoride level in food and beverage industry has become increasingly important in order to make sure the level of consumption of fluoride is monitored [9]. ${ }^{19} \mathrm{~F}$ NMR or electrode sensors are very sensitive but require expensive instrumentation and maintenance [10]. Therefore, the quest for a good sensor is increasingly important [11]. Some of the desirable properties of sensors are easy operation, sensitivity and cost efficiency [12]. Study of the mechanism of sensing becomes vital for the construction of better chemosensors. Several mechanisms have been proposed to understand the mechanism of sensing; popular ones being photo induced electron transfer (PET), internal charge transfer (ICT), and hydrogen bonding between the anion and the receptor. Particularly in the case of fluoride, the mechanism of hydrogen bonding is highly accepted due to its high electronegativity [13 - 17].

Our current work deals with the chemosensing behaviour of 2-hydroxyacetophenone nicotinic acid hydrazone $\left(\mathrm{H}_{2} \mathrm{~L}\right)$ towards fluoride anion. Similar hydrazides have been synthesized and studied [18, 19]. The presence of hydrogen bond donors in acid hydrazone derivatives strongly suggest the presence of hydrogen bonding between $\mathrm{H}_{2} \mathrm{~L}$ and the anion which gave rise to a colored complex. 
<smiles>C/C(=N\NC(=O)c1cccnc1)c1ccccc1O</smiles>

Figure 1. Structure of the receptor $-H_{2} L$.

\section{Experimentation}

All computational calculations were carried out using Gaussian 16 software package. Ground state geometry optimization was performed using hybrid exchangecorrelation density functional with B3LYP method using 6$311 \mathrm{G}+(\mathrm{d}, \mathrm{p})$ as basis set. Both receptor and receptor with fluoride were geometrically optimized and their NMR and IR spectra were recorded. The ${ }^{1} \mathrm{H}$ NMR spectra was carried out using the gauge-invariant atomic orbital method (SCF GIAO magnetic shielding) where TMS B3LYP/6-311+G(2d,p) GIAO was used as a reference. The fundamental vibrations involving the prominent $\mathrm{N}$ atom has been analyzed in corresponding bandwidth and the variation in fundamental frequencies have been noted. The solvent acetonitrile was incorporated using Polarizable Continuum Model (PCM) using the integral equation formalism variant (IEFPCM).

Synthesis scheme of $\mathrm{H}_{2} \mathrm{~L}$

The substituted acid hydrazone receptor, 2hydroxyacetophenone nicotinic acid hydrazine $\left(\mathrm{H}_{2} \mathrm{~L}\right)$ was synthesized from an equimolar ratio of hydroxyacetophenone and nicotinic acid hydrazide [20]. This was refluxed for 7 hours with methanol as a solvent. The product obtained was crystallized and confirmed using ${ }^{1} \mathrm{H}$ NMR.

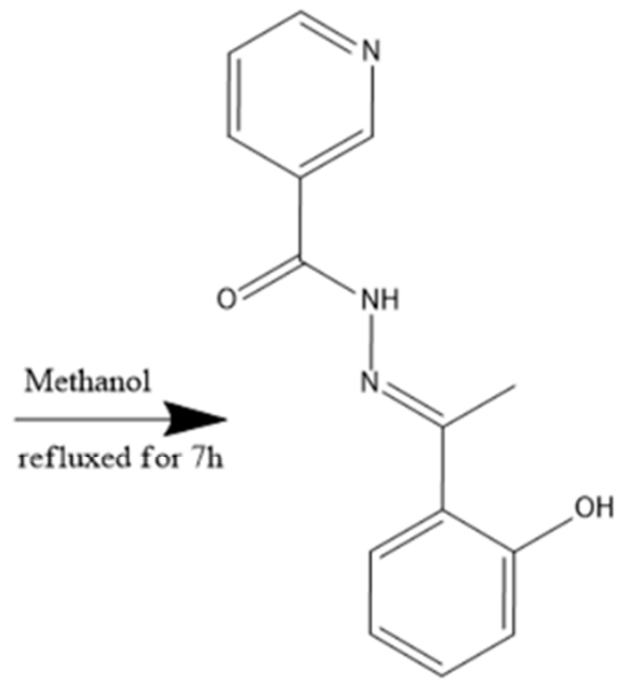

Figure 1. Synthetic scheme of $\mathrm{H}_{2} L$.

\section{Results and Discussions}

The receptor synthesized using the above procedure was tested with the TBA salt of fluoride and the solution turned yellow. The observation was the same for other fluoride sources while it remained colourless with non-fluoride substances.

\subsection{UV-Visible Spectral Studies}

The color obtained on adding fluoride can be explained using electronic spectroscopy. The UV-vis spectra of $\mathrm{H}_{2} \mathrm{~L}$ and $\mathrm{H}_{2} \mathrm{~L}$ with fluoride $\left(\mathrm{H}_{2} \mathrm{~L}-\mathrm{F}\right)$ were recorded using acetonitrile as the solvent (Figure 3). An absorption maximum was observed at $281 \mathrm{~nm}$ for $\mathrm{H}_{2} \mathrm{~L}$. On addition of fluoride, a decrease in the intensity of the peak corresponding to $\mathrm{H}_{2} \mathrm{~L}$ was observed while a new peak was formed at $374 \mathrm{~nm}$. This peak could be attributed to the deprotonated form of the receptor. Although, the hydrogen bonded species is formed, the color developed is prominently due to the deprotonated form.

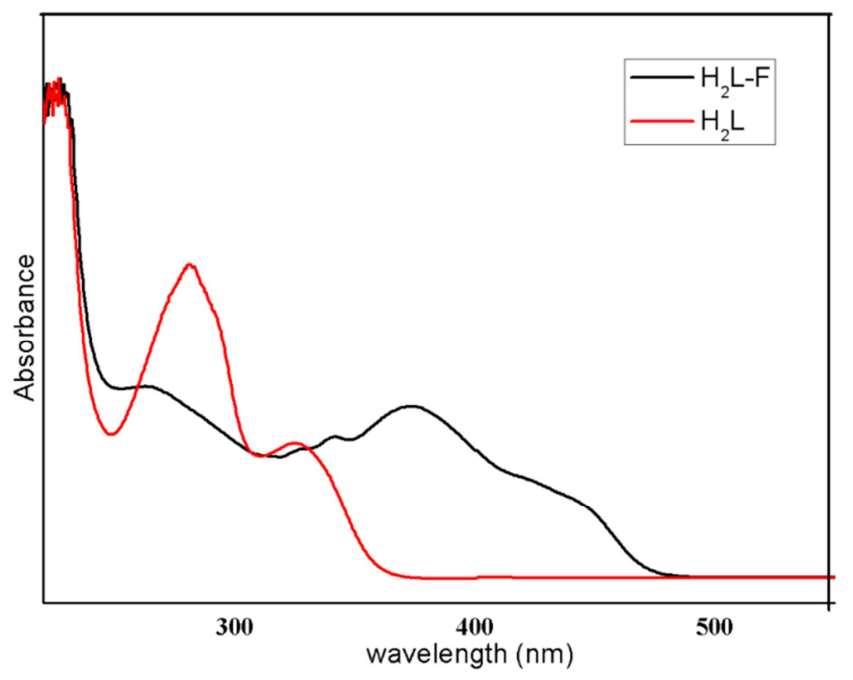

Figure 2. UV-vis spectrum. 


\subsection{Geometry Optimization}

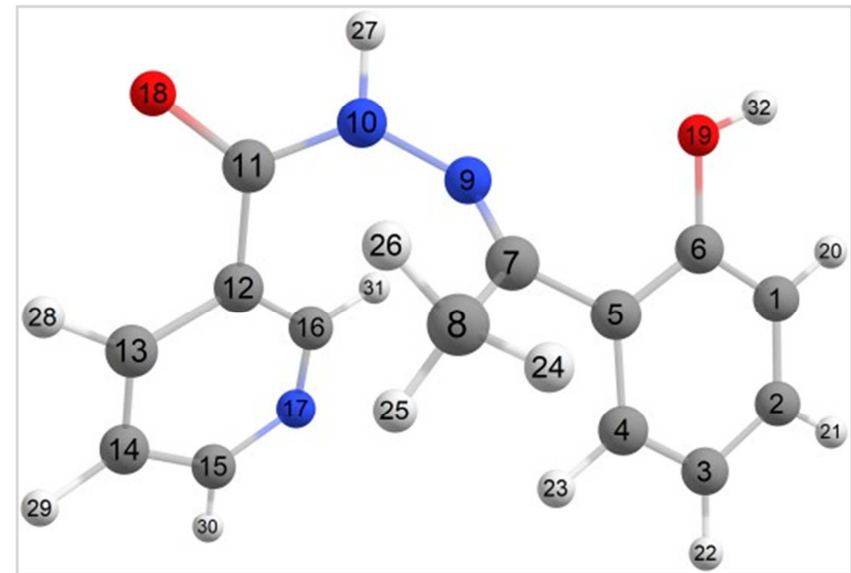

(a)

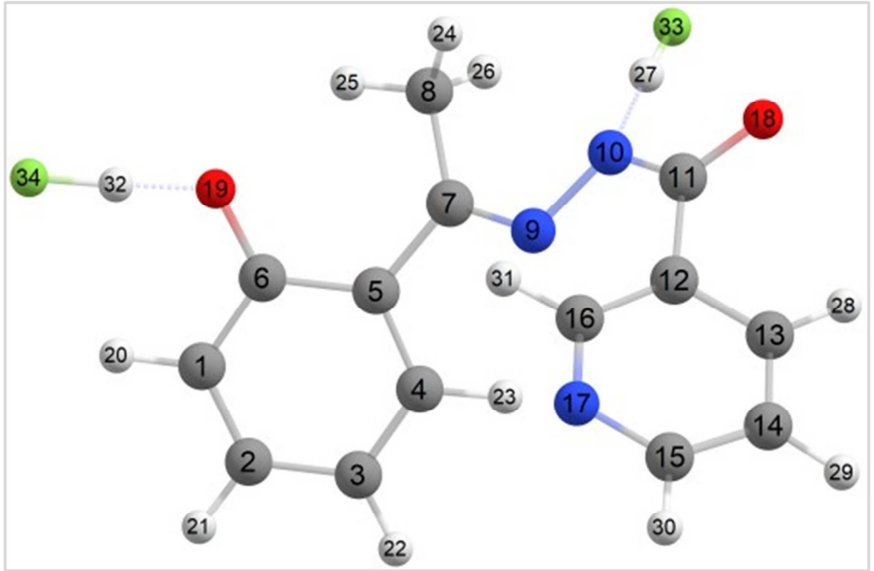

(b)

Figure 3. Geometry optimized structure of (a) $\mathrm{H}_{2} L$ (b) $\mathrm{H}_{2} L-F$ (grey - C, white - H, blue - N, green - F, red - O).

The geometry optimization suggested that the N-H and O$\mathrm{H}$ protons have higher affinity towards the highly basic fluoride (Figure 4). The N-H bond distance was observed to increase from $1.01313 \AA$ A to $1.49251 \AA$ and $\mathrm{O}-\mathrm{H}$ bond distance was observed to increase from $0.964996 \AA$ to $1.26251 \AA$ for $\mathrm{H}_{2} \mathrm{~L}$ and $\mathrm{H}_{2} \mathrm{~L}-\mathrm{F}$ complex respectively. $\mathrm{A}$ new bond with fluoride with bond distances $1.026 \AA$ and $1.09962 \AA$ for $\mathrm{N}-\mathrm{H}$ and $\mathrm{O}-\mathrm{H}$ protons were observed respectively. It can therefore be inferred that there exists a hydrogen bond in $\mathrm{H}_{2} \mathrm{~L}-\mathrm{F}$ complex $[13,21,22]$.

\section{3. ${ }^{1}$ H NMR Spectral Analysis}

The receptor $\mathrm{H}_{2} \mathrm{~L}$ was studied before and after the addition of fluoride using theoretical and experimental methods.

\subsubsection{Theoretical Calculations}
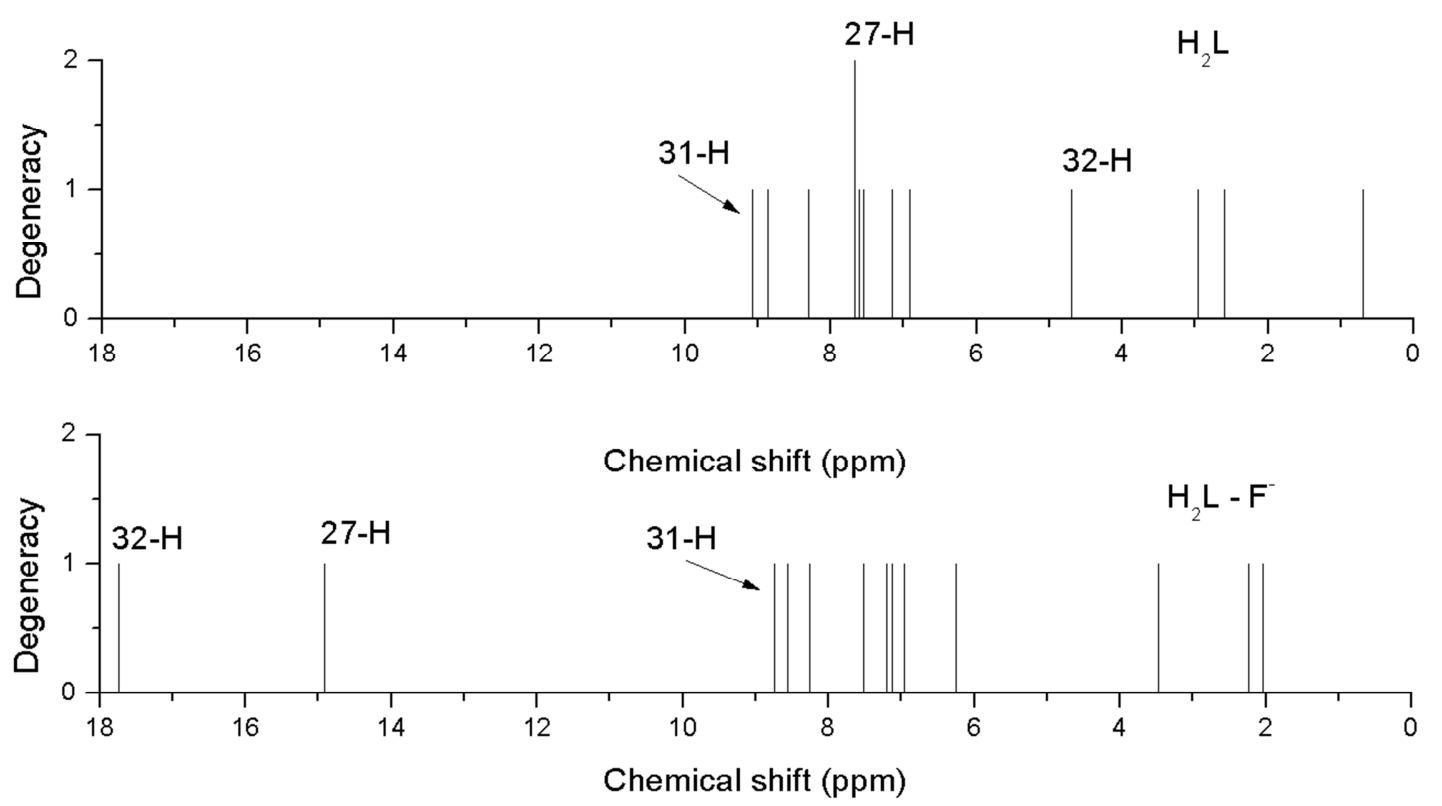

Figure 4. ${ }^{1} \mathrm{H} N \mathrm{NR}$ of $\mathrm{H}_{2} \mathrm{~L}$ and $\mathrm{H}_{2} L-F$ using GIAO method.

The theoretical calculations were carried out by using B3LYP density functional using $6311 \mathrm{~g}+(\mathrm{d}$, $\mathrm{p})$ as the basis set using GIAO method with acetonitrile as solvent where TMS B3LYP/6311+G $\left(2 \mathrm{~d}\right.$, p) was taken as reference. The ${ }^{1} \mathrm{H}$ NMR for the receptor showed peaks at 7.67 and 4.60 ppm for N-H and O-H protons respectively. After the addition of fluoride, the N-H and $\mathrm{O}-\mathrm{H}$ peaks were observed at 14.9091 and $17.7368 \mathrm{ppm}$ respectively (Figure 5). This suggested the increased de-shielding around $\mathrm{N}-\mathrm{H}$ and $\mathrm{O}-\mathrm{H}$ protons after the addition of fluoride indicating the movement of protons towards the highly basic fluoride anion. This can be visualized as a hydrogen bonded complex. 


\subsubsection{Experimental Results}

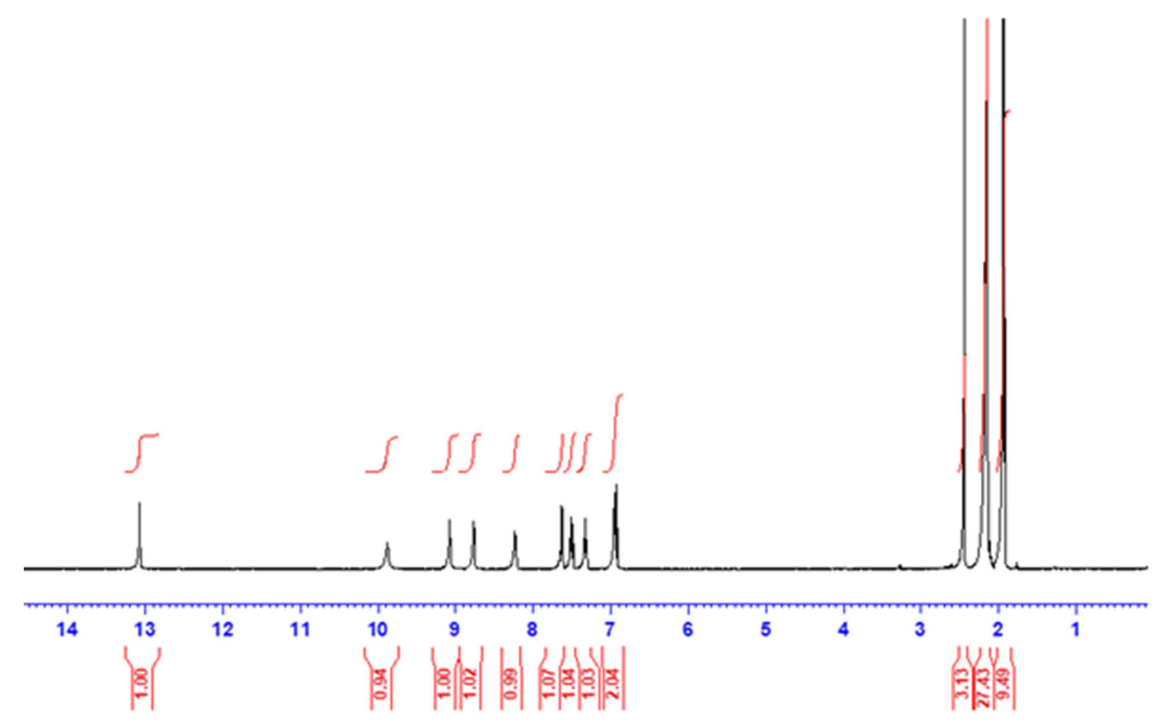

(a)

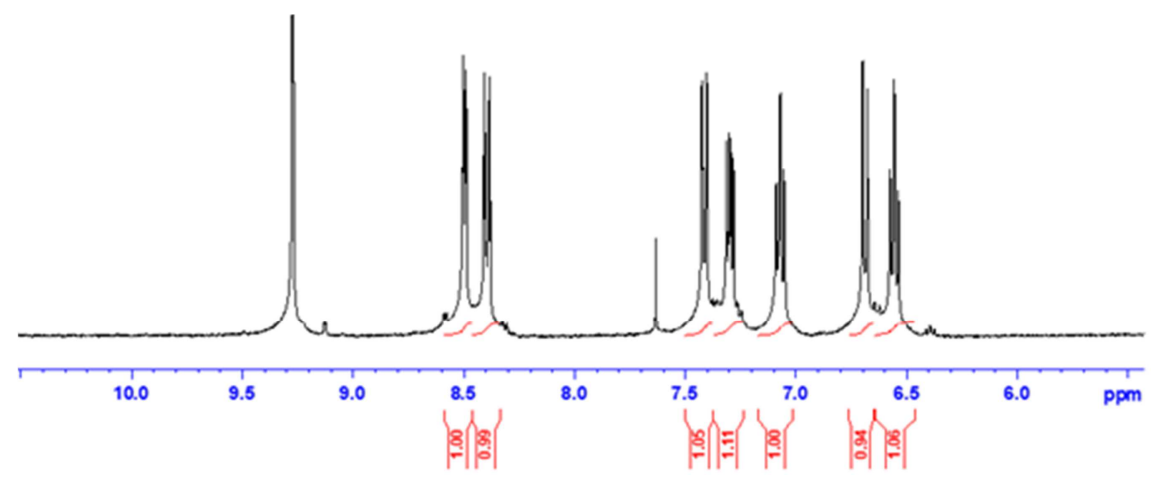

(b)

Figure 5. (a) ${ }^{l} H$ NMR spectrum of $\mathrm{H}_{2} L$ (b) enlarged view.

Experimentally the N-H and O-H protons for the receptor were observed at 9.880 ppm and 13.074 ppm (Figure 6). Upon addition of considerable amount of fluoride, the peaks were found to disappear indicating the deprotonated state of the receptor (Figure 7).

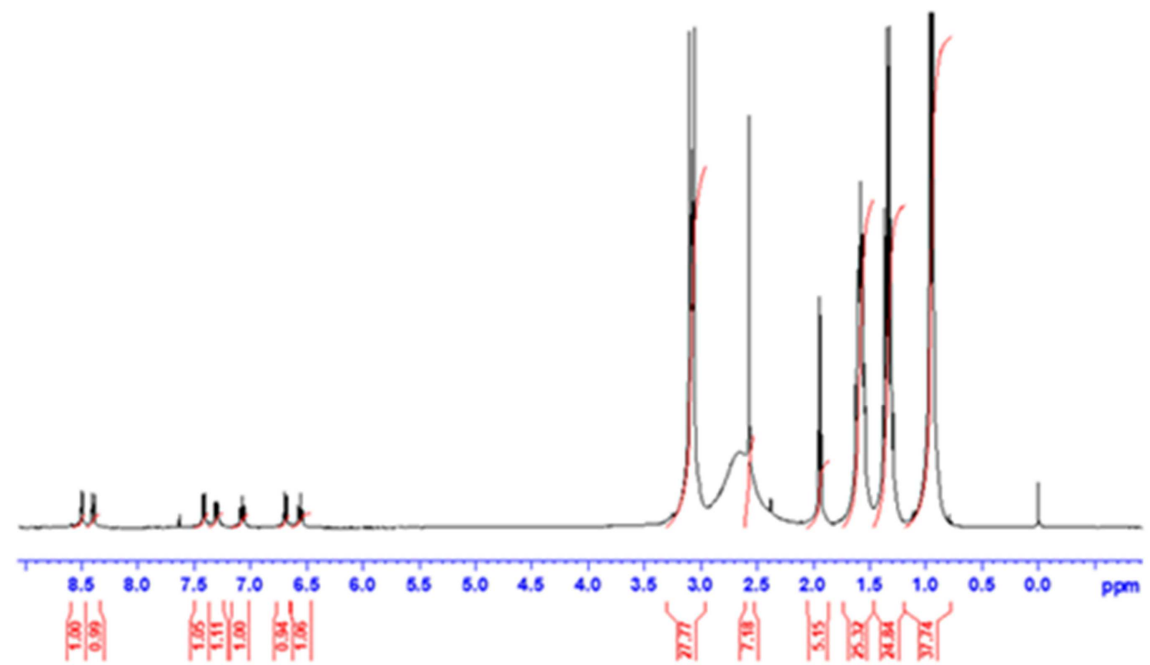

(a) 


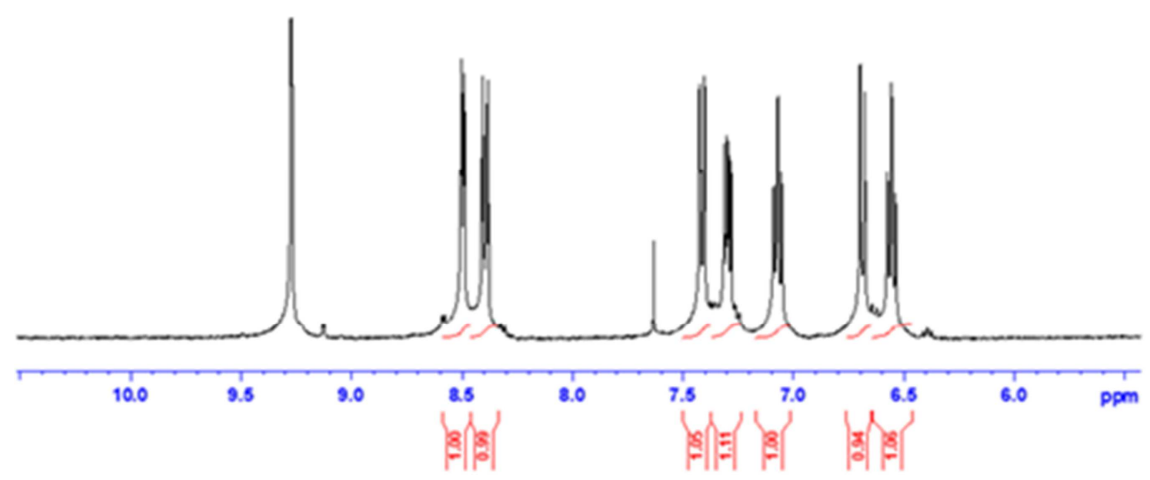

(b)

Figure 6. (a) ${ }^{l} H N M R$ spectrum of $H_{2} L-F$ (b) enlarged view.

Table 1. Comparison of ${ }^{l} H$ NMR peaks (in ppm).

\begin{tabular}{lllll}
\hline \multirow{2}{*}{ Proton No. } & Theoretical & & Experimental & \\
\cline { 2 - 5 } & $\mathbf{H}_{\mathbf{2}} \mathbf{L}$ & $\mathbf{H}_{\mathbf{2}} \mathbf{L}-\mathbf{F}$ & $\mathbf{H}_{2} \mathbf{L}$ & $\mathbf{H}_{2} \mathbf{L}-\mathbf{F}$ \\
\hline $32-\mathrm{H}$ & 4.6964 & 17.7368 & 9.880 & - \\
$27-\mathrm{H}$ & 7.6719 & 14.9091 & 13.074 & - \\
\hline
\end{tabular}

\subsection{IR Spectral Analysis}

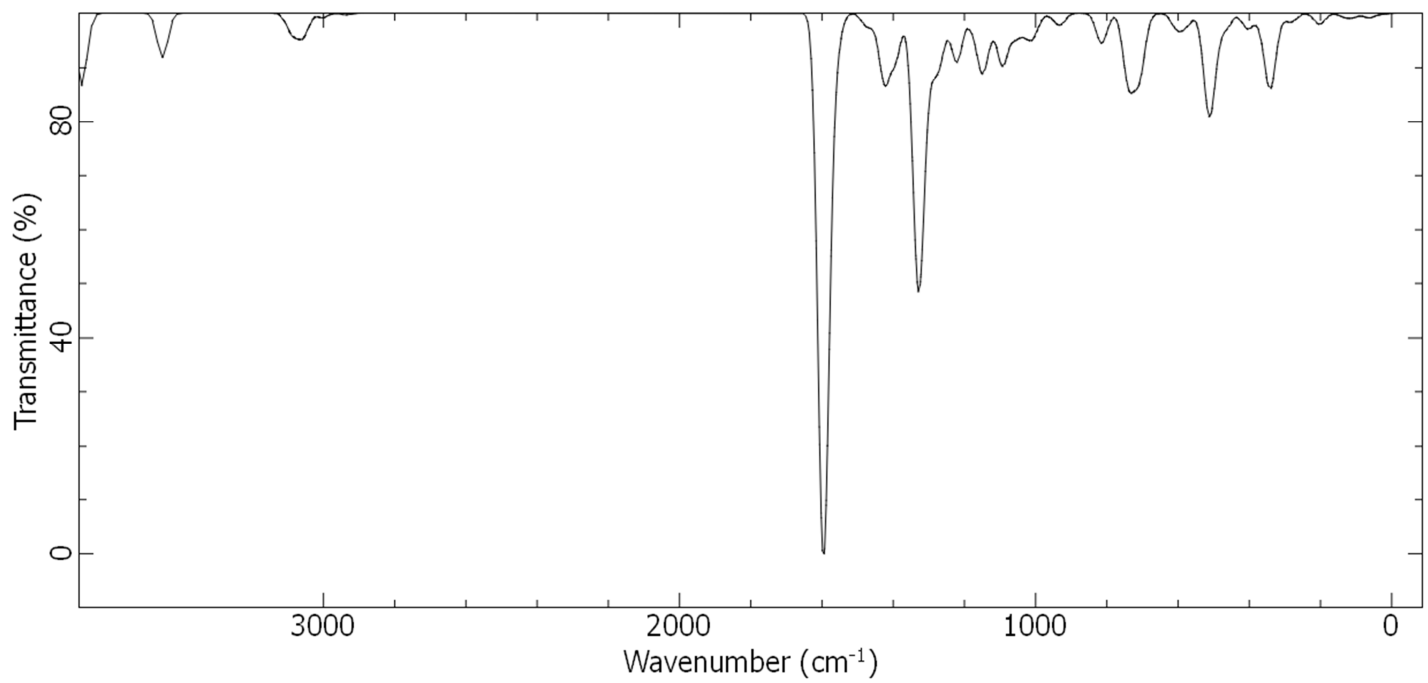

Figure 7. Vibrational spectrum of $H_{2} L$ using 6-311G B3LYP.

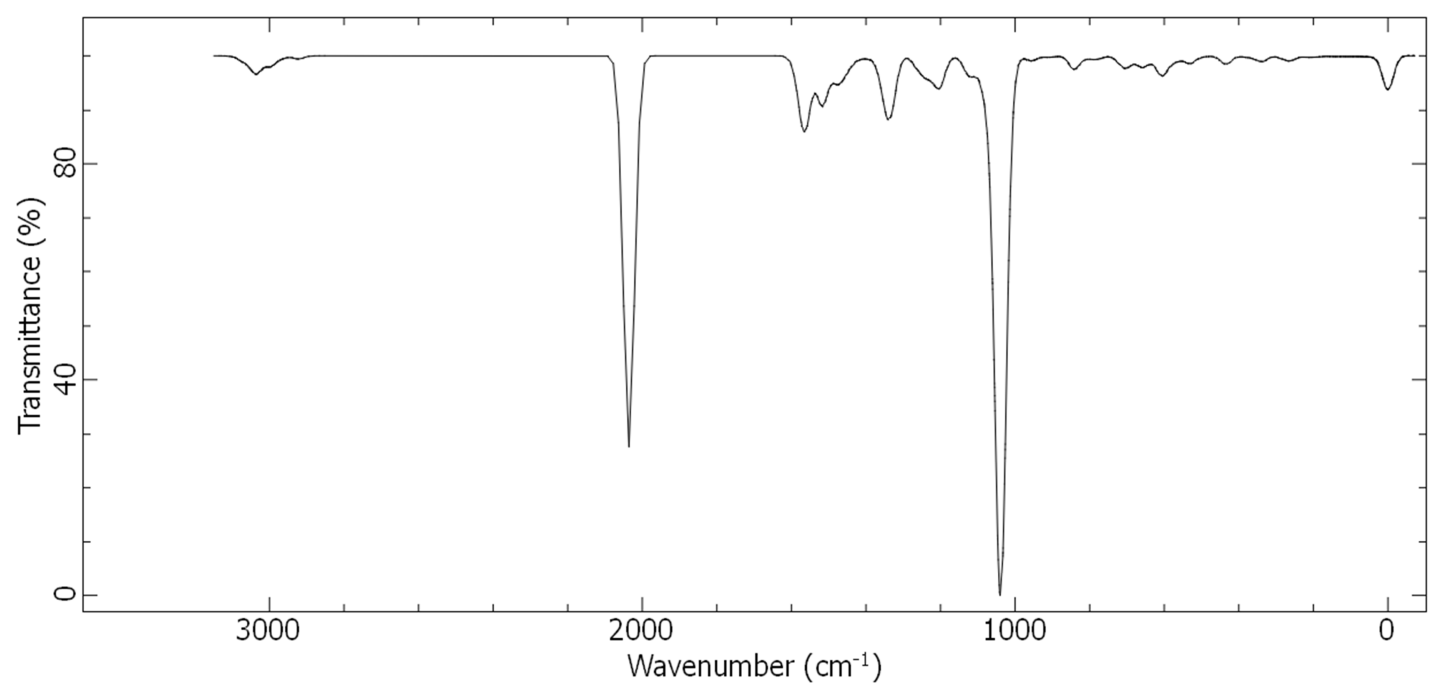

Figure 8. Vibrational spectrum of $\mathrm{H}_{2} L-F$ using 6-311G B3LYP. 
To monitor the changes occurring at the N-H and O-H sites on adding fluoride, experimental and computational IR spectra were recorded for both $\mathrm{H}_{2} \mathrm{~L}$ and $\mathrm{H}_{2} \mathrm{~L}-\mathrm{F}$. The experimental IR spectra for the receptor $\mathrm{H}_{2} \mathrm{~L}$ gave rise to N$\mathrm{H}$ and $\mathrm{O}-\mathrm{H}$ peaks at $3020 \mathrm{~cm}^{-1}$ and $3300 \mathrm{~cm}^{-1}$ respectively. On addition of fluoride the $\mathrm{N}-\mathrm{H}$ and $\mathrm{O}-\mathrm{H}$ peaks were not observed, this suggests the abstraction of the protons by the highly basic fluoride anion (Figure 10).

Geometry optimized structures of $\mathrm{H}_{2} \mathrm{~L}$ and $\mathrm{H}_{2} \mathrm{~L}-\mathrm{F}$ were used to calculate the IR absorption intensities using B3LYP method and $6-311+\mathrm{G}(\mathrm{d}, \mathrm{p})$ as the basis set. The calculated frequencies were scaled by a scaling factor of 0.964 to reduce the deviation between theoretical and experimental results. The computational IR spectra results were in accordance with the experimental data (Figure 8).

On adding fluoride anion, the O-H peak was not observed, and the huge red shift of the $\mathrm{N}-\mathrm{H}$ peaks suggested deprotonation (Figure 9).
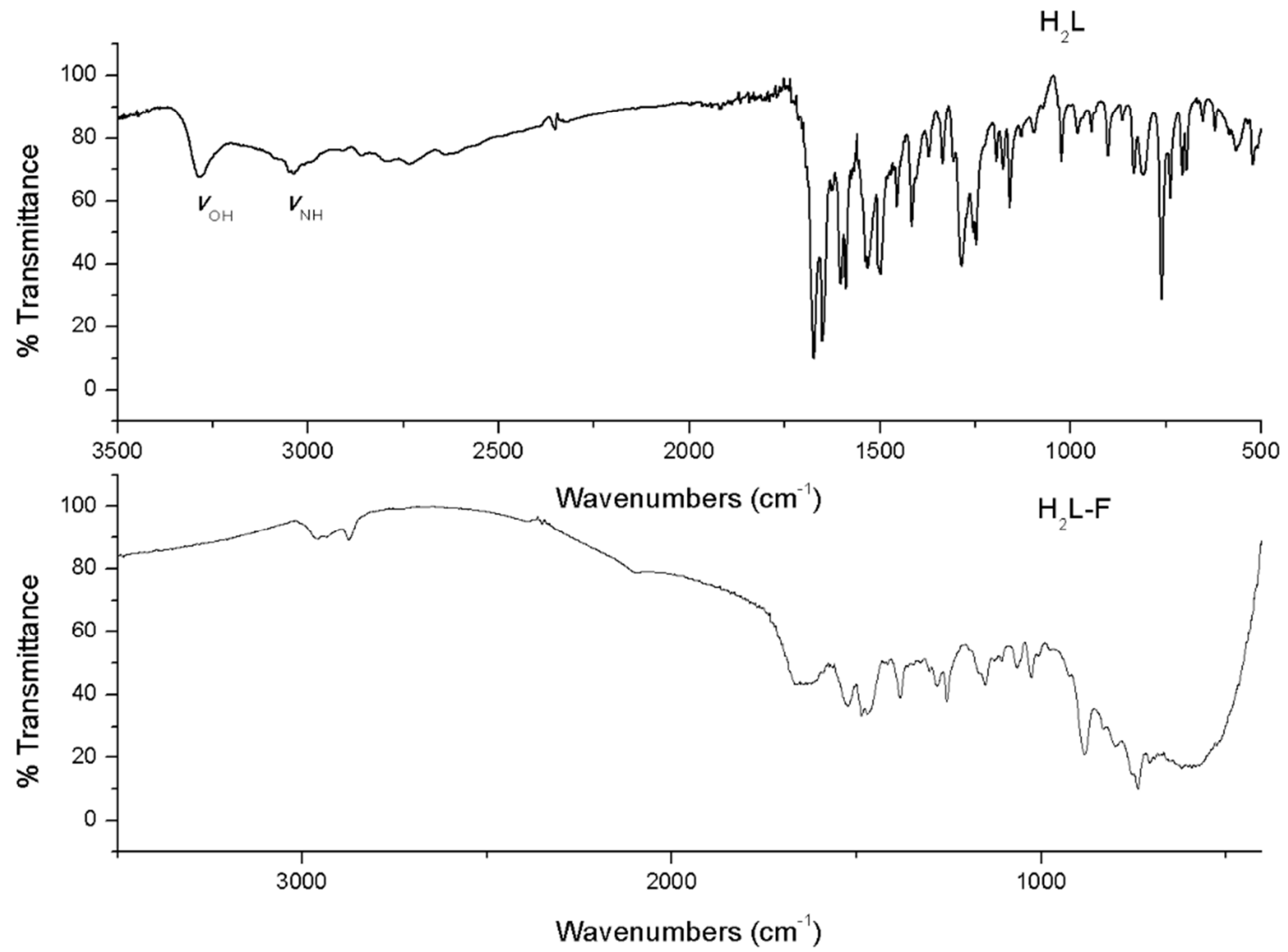

Figure 9. IR spectra of $\mathrm{H}_{2} L$ and $\mathrm{H}_{2} L-F$.

Table 2. Comparison of IR spectra.

\begin{tabular}{lllll}
\hline & \multicolumn{2}{l}{ Theoretical } & \multicolumn{3}{c}{ Experimental } \\
\cline { 2 - 5 } & $\mathbf{H}_{\mathbf{2}} \mathbf{L}$ & $\mathbf{H}_{\mathbf{2}} \mathbf{L}-\mathbf{F}$ & $\mathbf{H}_{\mathbf{2}} \mathbf{L}$ & $\mathbf{H}_{\mathbf{2}} \mathbf{L}-\mathbf{F}$ \\
\hline $\mathrm{V}_{\mathrm{NH}}$ & 3056 & 2010 & 3020 & - \\
$\mathrm{V}_{\mathrm{OH}}$ & 3442 & - & 3300 & - \\
\hline
\end{tabular}

\section{Conclusion}

The receptor was found to be a very effective fluoride sensor in acetonitrile. This was proved using UV-Vis, IR and ${ }^{1} \mathrm{H}$ NMR experiments. The computational studies provided a useful insight on the mechanism of sensing. The mechanism is shown to involve a hydrogen bonded complex which was deprotonated at appreciable concentrations of fluoride. Selectivity of the receptor towards fluoride over other anions was tested. It could be a potential sensor for heavy metals like lead, copper, etc.

The hydrophobic nature of the receptor limits its use to organic aprotic solvents. More work must be done on increasing the hydrophilic nature of the receptor, so that fluoride anion in aqueous environment can be sensed and quantitatively detected. Increasing the polar groups on the receptor might improve the solubility in aqueous medium but the proton donation ability of water is much better compared to the receptor in aqueous medium and hence the receptor must be designed in a way that the hydrogen bond donors of the receptors competes with water molecules to abstract the protons to act as a sensor in aqueous medium.

\section{Acknowledgements}

The authors would like to acknowledge Dr. Jaleel UC from Open Source Pharma Foundation for his guidance and Dr. Remalakshmy Poduval of DB college for her help and support with the project. 


\section{References}

[1] M. Saravana Kumar, S. L. Ashok Kumar, and A. Sreekanth, "Highly selective fluorogenic anion chemosensors: naked-eye detection of $\mathrm{F}-$ and $\mathrm{AcO}-$ ions in natural water using a test strip," Anal. Methods, vol. 5, no. 22, p. 6401, 2013.

[2] J. Wergedal, D. Baylink, and others, "Fluoride directly stimulates proliferation and alkaline phosphatase activity of bone-forming cells," Science, vol. 222, no. 4621, pp. 330-332, 1983.

[3] R. Martinez-Manez and F. Sancenón, "Fluorogenic and chromogenic chemosensors and reagents for anions," Chem. Rev., vol. 103, no. 11, pp. 4419-4476, 2003.

[4] T. Gunnlaugsson, M. Glynn, G. M. Tocci (née Hussey), P. E. Kruger, and F. M. Pfeffer, "Anion recognition and sensing in organic and aqueous media using luminescent and colorimetric sensors," Coord. Chem. Rev., vol. 250, no. 23-24, pp. 3094-3117, Dec. 2006.

[5] R. Yang, W.-X. Liu, H. Shen, H.-H. Huang, and Y.-B. Jiang, "Anion Binding in Aqueous Solutions by N(Isonicotinamido)-N '-phenylthiourea-Based Simple Synthetic Neutral Receptors. Role of the Hydrophobic Microenvironment of the Receptor Molecule," J. Phys. Chem. $B$, vol. 112, no. 16, pp. 5105-5110, 2008.

[6] D. Briançon, "Fluoride and osteoporosis: an overview.," Rev. Rhum. Engl. Ed, vol. 64, no. 2, pp. 78-81, 1997.

[7] M. Kleerekoper, "The role of fluoride in the prevention of osteoporosis," Endocrinol. Metab. Clin., vol. 27, no. 2, pp. 441-452, 1998.

[8] H. F. Pollick, "Water fluoridation and the environment: current perspective in the United States," Int. J. Occup. Environ. Health, vol. 10, no. 3, pp. 343-350, 2004.

[9] F. Zohoori and A. Maguire, "Should food and drink have fluoride labels?," BDJ Team, vol. 5, no. 6, p. 18088, 2018.

[10] K. Itai and H. Tsunoda, "Highly sensitive and rapid method for determination of fluoride ion concentrations in serum and urine using flow injection analysis with a fluoride ionselective electrode," Clin. Chim. Acta, vol. 308, no. 1-2, pp. 163-171, 2001.

[11] M. Karar, S. Paul, A. Mallick, and T. Majumdar, "Interaction Behavior between Active Hydrogen Bond Donor-Acceptors as a Binding Decoration for Anion Recognition: Experimental Observation and Theoretical Validation," ChemistrySelect, vol. 2, no. 9, pp. 2815-2821, Mar. 2017.

[12] J. Joseph and E. D. Jemmis, "Red-, Blue-, or No-Shift in Hydrogen Bonds: A Unified Explanation," J. Am. Chem. Soc., vol. 129, no. 15, pp. 4620-4632, Apr. 2007.

[13] S. A. Kumar, M. S. Kumar, P. Sreeja, and A. Sreekanth, "Novel heterocyclic thiosemicarbazones derivatives as colorimetric and 'turn on' fluorescent sensors for fluoride anion sensing employing hydrogen bonding," Spectrochim. Acta. A. Mol. Biomol. Spectrosc., vol. 113, pp. 123-129, 2013.

[14] G.-Y. Li, G.-J. Zhao, Y.-H. Liu, K.-L. Han, and G.-Z. He, "TD-DFT study on the sensing mechanism of a fluorescent chemosensor for fluoride: Excited-state proton transfer," $J$. Comput. Chem., p. NA-NA, 2010.

[15] R. Hu et al., "A Rapid Aqueous Fluoride Ion Sensor with Dual Output Modes," Angew. Chem. Int. Ed., vol. 49, no. 29, pp. 4915-4918, Jun. 2010.

[16] B. Zhu, H. Kan, J. Liu, H. Liu, Q. Wei, and B. Du, “A highly selective ratiometric visual and red-emitting fluorescent dualchannel probe for imaging fluoride anions in living cells," Biosens. Bioelectron., vol. 52, pp. 298-303, Feb. 2014.

[17] S. D. Shahida Parveen, B. Suresh Kumar, S. Raj Kumar, R. Imran Khan, and K. Pitchumani, "Isolation of biochanin A, an isoflavone, and its selective sensing of copper (II) ion," Sens. Actuators B Chem., vol. 221, pp. 75-80, Dec. 2015.

[18] P. Sreeja, M. Sithambaresan, N. Aiswarya, and M. P. Kurup, "N'-[(E)-2-Fluorobenzylidene] benzohydrazide," Acta Crystallogr. Sect. E Struct. Rep. Online, vol. 69, no. 12, pp. o1828-o1828, 2013.

[19] J. Jose, A. Sreekanth, A. M. John, S. M. Basheer, and P. Sreeja, "Spectrochemical and theoretical approaches for acylhydrazone-based fluoride sensors," Res. Chem. Intermed., pp. 1-11, 2018.

[20] P. Sreeja and M. P. Kurup, "Synthesis and spectral characterization of ternary complexes of oxovanadium (IV) containing some acid hydrazones and 2, 2'-bipyridine," Spectrochim. Acta. A. Mol. Biomol. Spectrosc., vol. 61, no. 12, pp. 331-336, 2005.

[21] R. S. Bhosale, M. M. Kelson, S. V. Bhosale, S. K. Bhargava, and S. V. Bhosale, "Amphiphilic push-pull iminocoumarin for colorimetric selective fluoride anion sensing," Mater. Today Proc., vol. 3, no. 6, pp. 1883-1889, 2016.

[22] H. Ozay, M. Yildirim, and O. Ozay, "Synthesis, Characterization, and Naked-Eye Sensor Application of Fully Substituted Urea-Based Cyclotriphosphazene Compound," Phosphorus Sulfur Silicon Relat. Elem., vol. 190, no. 11, pp. 1865-1873, 2015. 